\title{
Expression Analysis of Matrix Metalloproteinase-9 Gene in Rheumatoid Arthritis Patients on Disease Modifying Anti-Rheumatic Drugs
}

\author{
Farzana Hakim¹, Amir Rashid ${ }^{1}$, Amer Fakhr ${ }^{3}$ and Saleem Ahmed Khan²
}

\begin{abstract}
Objective: To evaluate matrix metalloproteinase-9 gene expression in rheumatoid arthritis patients on disease modifying anti-rheumatic agents with the objective to further modify the current treatment regimen if indicated in order to prevent progression to deforming rheumatoid arthritis.

Study Design: Cross-sectional comparative study.

Place and Duration of Study: CREAM Lab (Centre for Research in Experimental and Applied Medicine) and Department of Biochemistry and Molecular Biology, Army Medical College, in collaboration with Rheumatology Department at Military Hospital Rawalpindi from November 2015 to November 2016.

Methodology: A total of 60 patients of both genders were taken, among which 30 were patients and 30 were controls. Non-probability purposive sampling technique was used. RNA was extracted from respective blood sample and cDNA was synthesised and after optimisation, expression analysis of matrix metalloproteinase-9 gene was seen on real time PCR. Results: Mean age of rheumatoid arthritis patients and healthy controls was $49.27 \pm 12.11$ and $42.10 \pm 9.02$ years, respectively. Among controls, $50 \%$ were males (15) and $50 \%$ were females (15); whereas, among patients, $30 \%$ (9) were males and $70 \%$ (21) were females. The mean cycle threshold (Ct) value of MMP-9 expressions in patients was 27.9147 \pm 2.953 ; whereas, mean Ct of controls was $23.84 \pm 2.845$. Down regulation of this gene was found in patients in comparison to controls.

Conclusion: Downregulation of matrix metalloproteinase- 9 was observed in patients as compared to controls indicating that current treatment regimen did not require further modification.
\end{abstract}

Key Words: Disease modifying anti-rheumatic drugs, matrix metalloproteinase-9 gene, Rheumatoid arthritis, Gene expression, Real time PCR.

\section{INTRODUCTION}

Rheumatoid arthritis (RA) is an autoimmune chronic systemic inflammatory disease. ${ }^{1}$ RA along with extra articular manifestations and comorbidities results in increased mortality. ${ }^{2}$ It has victimised about $1 \%$ of the population around the world. ${ }^{2}$ In southern and northern Pakistan, the RA prevalence is stated to be $0.142 \%,{ }^{3}$ and $0.55 \%$, respectively. 4,5

Matrix metalloproteinases (MMPs) were discovered in 1960. To date, 25 different MMPs have been identified, of which 24 different MMPs are found in humans. MMP-9 is a member of gelatinases subgroup which has ability of gelatin degradation. MMP-9 is involved in joint destruction in RA.6-10 It is present in humans on chromosome 20. It has 13 exons and has two distinctive domains, fibronectin-like domain, and hemopexin

1 Department of Biochemistry / Pathology², Army Medical College, Rawalpindi, Pakistan

3 Department of Rheumatology, Military Hospital, Rawalpindi, Pakistan

Correspondence: Dr. Farzana Hakim, Department of Biochemistry, Army Medical College, Rawalpindi, Pakistan E-mail:farzanahakim2@gmail.com

Received: November 06, 2017; Accepted: July 03, 2018 domains which is involved in TIMPs (tissue inhibitor of metalloproteinases) binding. The fibronectin-like domain is essential in binding to denatured collagen or gelatin; thus playing active role in ECM degradation. ${ }^{11}$ In 2010, American College of Rheumatology (ACR) as well as European League Against Rheumatism (EULAR) jointly set new RA classification criteria. ${ }^{12}$ Two major classifications of anti-rheumatic drugs, i.e. conventional synthetic disease-modifying anti-rheumatic drugs (csDMARDs) such as Methotrexate, Leflunamide, Hydroxychloroquin, Azathoprine etc and biologic DMARDs (bDMARD) like anti-TNFi, Rituximab, Tociliumab have revolutionised the $R A$ treatment.

This study will contribute in the research work being done anywhere in the world in this regard. This study can be useful for the clinicians for timely modification of DMARDs in non-responding RA patients to prevent progression to deforming RA.

The objective of this research was to study expression analysis of matrix metalloproteinase-9 gene among rheumatoid arthritis patients on DMARDs and healthy controls.

\section{METHODOLOGY}

The study project was approved by Ethical Committee of Army Medical College, Rawalpindi. The study was 
conducted at Department of Biochemistry and Molecular Biology, Army Medical College, Rawalpindi in collaboration with Department of Rheumatology in Military Hospital, Rawalpindi (MH). Molecular analysis was carried out at Centre for Research in Experimental and Applied Medicine (CREAM), Army Medical College. The duration of study was one year, from November 2015 to November 2016. Sample size was calculated by WHO calculator. It was a cross-sectional comparative study using purposive (non-probability) sampling technique. Patients were enrolled, and written consents were taken. The study included two groups: Group I comprised of normal healthy subjects $(n=30)$ and Group II included 30 patients; both males and females between 30-55 years of age that were diagnosed with rheumatoid arthritis and receiving DMARDs therapy. Patients having chronic arthritis other than RA or receiving immunosuppressant therapy were excluded from the study.

Blood samples were taken from both patients and controls. These samples were stored in EDTA tubes and were transported to CREAM lab on dry ice within half an hour to avoid degradation of RNA. Afterwards RNA extraction was performed according to the standard kit protocol. Extracted RNA was stored at $-80^{\circ} \mathrm{C}$. Specific primers were designed for target gene (MMP-9) and reference gene Glyceraldehyde phosphate dehydrogenase (GAPDH) on the basis of available INFARI sequence on National Centre for Biotechnology Information (NCBI). Primers were designed using different websites and their validity was checked using the websites, i.e. Primer BLAST: http://www.ncbi.nlm.nih.gov/ tools/primer-blast/. Gen Bank AccessionNM_004994, GAPDH primers; Forward 5'GCTCTCTGCTCCTGTTC 3'; Reverse 5'TTCCCGTTCTCAGCCTTGAC 3'; MMP-9 primers Forward 5' GGTGATTGACGACGCCTTTG 3'; Reverse 5' GAAATGGGCGTCTCCCTGAA 3'. Complementary deoxyribonucleic acid (cDNA) was synthesised from RNA by reverse transcription reaction using reverse transcriptase Revert aid first strand CDNA synthesis kit (Thermo scientific). PCR machine (Corbet Inc) was optimised so that the best amplification was obtained which was used in real time PCR. The dye used was Maxima SYBR Green Master Mix by Thermoscientific USA.

Quantification of MMP-9 gene by RT-PCR (Cepheid smartcycler, USA) was done. Ct values were determined and fold change in expression of RA patients versus normal were calculated. Human GAPDH was used for normalisation.

Data was analysed using SPSS version 22. Numerical data was analysed by mean \pm S.D. Categorical data was analysed by frequencies and graphs. Relative quantification of gene expression was done using $\Delta \Delta \mathrm{Ct}$ method (Livak and Schmittgen, 2001).

\section{RESULTS}

Sixty subjects were recruited and divided into two groups. The subjects of both groups were analysed for the expression analysis of MMP-9 gene. In group I of healthy controls, $50 \%$ were males (15) and $50 \%$ were females (15); whereas, among Group II of RA patients, $30 \%$ (9) were males and $70 \%$ (21) were females.

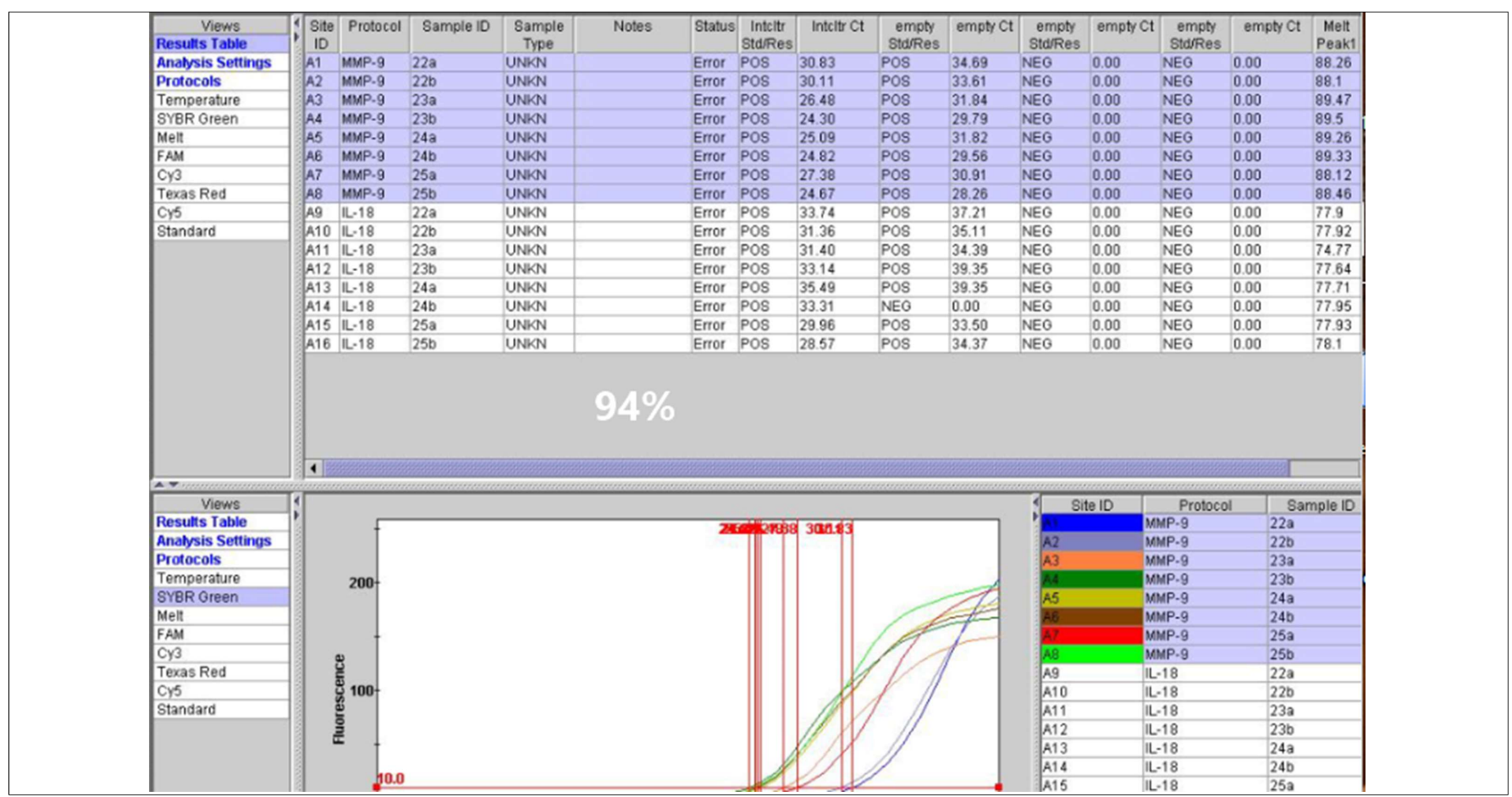

Figure 1: Real time PCR showing Ct values of MMP-9 of patients. 
Table I: Mean Ct and Ct values of MMP-9 gene in patients and controls.

\begin{tabular}{l|c|c|c|c|c}
\hline $\begin{array}{l}\text { Average experimental } \\
\text { Ct value }\end{array}$ & $\begin{array}{c}\text { Average experimental } \\
\text { Ct value }\end{array}$ & $\begin{array}{c}\text { Average control } \\
\text { Ct value }\end{array}$ & $\begin{array}{c}\text { Average control } \\
\text { Ct value }\end{array}$ & $\begin{array}{c}\text { Ct value } \\
\text { (Experimental) }\end{array}$ & $\begin{array}{c}\text { Ct value } \\
(\text { Control) }\end{array}$ \\
\hline TE $(M M P 9)$ & HE (GAPDH) & TC (MMP9) & HC (GAPDH) & CTE & CTC \\
\hline 27.9147 & 23.11 & 23.8480 & 24.0470 & 4.804 & -0.199 \\
\hline
\end{tabular}

In group I of healthy controls, mean age was 42.10 \pm 9.02 years; whereas, in group II of RA patients, mean age was $49.27 \pm 12.11$ years.

Gene expression analysis of MMP-9 was measured through real time PCR with reference gene taken as GAPDH. Multiple peaks showing Ct values of MMP-9 of patients is shown in Figure 1.

Ct values of MMP-9 and GAPDH of each patient and control was taken and $\triangle \mathrm{Ct}$ value was calculated. The mean Ct value of MMP-9 expressions in patients was $27.9147 \pm 2.953$; whereas, mean Ct value of controls was $23.84 \pm 2.845$. Mean $\triangle \mathrm{Ct}$ value of patients and controls was calculated as 4.804 and -0.199 , respectively as shown in Table I.

$\Delta \Delta \mathrm{Ct}$ was calculated from mean $\Delta \mathrm{Ct}$ value of patients and controls and found to be 4.283. Relative quantification was calculated from $\Delta \Delta \mathrm{Ct}$ value using formula $2^{\wedge}-\triangle \triangle \mathrm{Ct}$ and found to be 0.051 . It was observed that relative MMP-9 expression was significantly decreased in patients as compared to that in controls with $p$-value of 0.008 .

\section{DISCUSSION}

$R A$ is a chronic autoimmune systemic inflammatory disease, characterised by unswerving synovitis and severe bones and cartilage destruction, which deforms multiple joints. ${ }^{13}$ As RA is more common in females, this study also revealed a higher prevalence amongst females as compared to males; ratio being 2.3:1. An international study carried out in northern France showed this ratio, i.e. 2.99:1.14,15 Another study in Japan also exhibited that this disease is more prevalent in female, i.e. $2 \cdot 6: 1,16$ thus this ratio matches the international ratio.

MMP-9 gene is among the most studied MMPs gene, 17 and is reported to be directly related to disease activity of RA.7-11 High levels of MMP-9 were found in the synovial fluid of inflamed joints in RA patients in comparison to inflamed joints of osteoarthritis patients suggesting that although both are chronic forms of arthritis, but the joints destruction in RA is related to raised levels of pro-inflammatory MMP-9 resulting in increasing synovial fibroblast proliferation, migration, survival and invasion. ${ }^{18}$

In Taiwan, a study by Hsieh et al., showed that MMP-9 levels were elevated tenfold in RA synovial fluid compared with osteoarthritis (OA) synovial fluid. ${ }^{19}$ Xue et al. in 2007 observed a strong correlation between increased MMP-9 levels and the degree of inflammation in RA patients not receiving DMARDs. ${ }^{20,21}$

Another study conducted in USA in 2012 revealed, decreased MMP-9 expression in RA patients responding to DMARDs. Increase expression of MMP-9 was observed in RA patients not responding to DMARDs. Change to another DMARD or addition of biologic DMARDs resulted in significant reduction in MMP-9 levels. 22 Thus the results of this study matched our results and showed that decreased MMP-9 expression is directly linked to disease remission in RA patients. Similarly, research findings at Nasonova Research Institute of Rheumatology, Moscow, Russia, proved that RA patients showed decreased levels MMP-9 expression on DMARD. 23

Downregulation of MMP-9 gene was observed among RA patients receiving DMARDs therapy as compared to the normal healthy subjects. The same observation has been supported by the international studies cited above.

This study has some limitations. Due to scarcity of funds we were unable to take large sample size of both RA patients and controls. Baseline MMP-9 gene expression could not be taken as patients of RA included in the study were already on DMARDs.

Although RA is a non-curable disease, but if diagnosed and treated well in time, it improves quality of life. To achieve this aim, it is recommended that MMP-9 gene expression be included in the workup of all RA patients or at least those RA patients who are not responding to medication to modify treatment regimes in order to prevent permanent deformities.

\section{CONCLUSION}

DMARDs are effective in the treatment of RA patients in the Pakistani population as MMP-9 gene expression was downregulated. Response to DMARDs was equally seen in both genders. Therefore, no treatment modification was indicated in the study group.

\section{REFERENCES}

1. Harvey R, Ferrier D. Biochemistry (Lippincott's Illustrated Reviews Series). Lippincott Williams \& Wilkins, Baltimore, MD and Philadelphia, PA, USA; 2010.

2. Gibofsky A. Overview of epidemiology, pathophysiology, and diagnosis of rheumatoid arthritis. Am J Manag Care 2012; 18(13 Suppl):S295-302.

3. Hameed K, Gibson T, Kadir M, Sultana S, Fatima Z, Syed A. The prevalence of rheumatoid arthritis in affluent and poor 
urban communities of Pakistan. $\mathrm{Br} J$ Rheumatol 1995; 34: 252-6.

4. Farooqi A, Gibson T. Prevalence of the major rheumatic disorders in the adult population of north Pakistan. $\mathrm{Br} J$ Rheumatol 1998; 37:491-5.

5. Shamim R, Jan MD, Zafar U. Prevalenceof rheumatoid arthritis in population with arthralgia presenting to tertiary care. J Pak Med Assoc 2015; 65:1202-5.

6. Johnathan K, Katherine S. ACR/EULAR 2010 rheumatoid arthritis classification criteria BS J Rheumatol 2012; 51:10.

7. Kailina AN, Ogorodova LM, Chasovskikh I, Kremer EE. Indices of matrix metalloproteinases (MMP-2, MMP-9, TIMP-1) with juvenile arthritis in children. Vestn Ross Akad Med Nauk 2013; 7:36-40.

8. Li G, Zhang Y, Qian Y, Zhang H, Guo S, Sunagawa M, et al. Interleukin-17A promotes rheumatoid arthritis synoviocytes migration and invasion under hypoxia by increasing MMP2 and MMP9 expression through NF-kappaB/HIF-1alpha pathway. Mol Immunol 2013; 53:227-36.

9. Giannelli G, Erriquez R, lannone F, Marinosci F, Lapadula G, Antonaci S. MMP-2, MMP-9, TIMP-1 and TIMP-2 levels in patients with rheumatoid arthritis and psoriatic arthritis. Clin Exp Rheumatol 2004; 22:335-8.

10. Fiedorczyk M, Klimiuk PA, Sierakowski S, Domyslawska I, Chwiecko J. Correlations between serum matrix metalloproteinase (MMP-1, MMP-3, MMP-9, MMP-13) concentrations and markers of disease activity in early rheumatoid arthritis. Przegl Lek 2005; 62:1321-4.

11. de Rooy DP, Zhernakova A, Tsonaka R, Willemze A, Kurreeman BA, Trynka $G$, et al. A genetic variant in the region of MMP-9 is associated with serum levels and progression of joint damage in rheumatoid arthritis. Ann Rheum Dis 2014; 73: 1163-9.

12. Kim WU, Min SY, Cho ML, Hong KH, Shin YJ, Park SH, et al. Elevated matrix metalloproteinase- 9 in patients with systemic sclerosis. Arthritis Res Ther 2004; 7:R71.

13. Wei ST, Sun YH, Zong SH, Xiang YB. Serum levels of IL-6 and TNF- $\alpha$ may correlate with activity and severity of rheumatoid arthritis. Medical Science Monitor: International Medical J Exp Clin Res 2015; 21:4030-8.
14. Ngo ST, Steyn FJ, McCombe PA. Gender differences in autoimmune disease. Front Neuroendocrinol 2014; 35:347-69.

15. Biver E, Beague V, Verloop D, Mollet D, Lajugie D, Baudens G, et al. Low and stable prevalence of rheumatoid arthritis in northern France. Revue du Rhumatisme. 2009; 76:497-500.

16. Yamanaka H, Sugiyama N, Inoue E, Taniguchi A, Momohara S. Estimates of the prevalence of and current treatment practices for rheumatoid arthritis in Japan using reimbursement data from health insurance societies and the IORRA cohort (I). Mod Rheum 2014; 24:33-40.

17. Yabluchanskiy A, Ma Y, Iyer RP, Hall ME, Lindsey ML. Matrix metalloproteinase-9: Many shades of function in cardiovascular disease. Physiology 2013; 28:391-403.

18. Xue M, McKelvey K, Shen K, Minhas N, March L, Park S-Y, et al. Endogenous MMP-9 and not MMP-2 promotes rheumatoid synovial fibroblast survival, inflammation and cartilage degradation. Rheumatology 2014; 53:2270-9.

19. Hsieh MS, Ho HC, Chou DT, Pan S, Liang YC, Hsieh TY, et al. Expression of matrix metalloproteinase-9 (gelatinase B) in gouty arthritis and stimulation of MMP-9 by urate crystals in macrophages. J Cell Biochem 2003; 89:791-9.

20. Xue M, March L, Sambrook PN, Jackson CJ. Differential regulation of matrix metalloproteinase 2 and matrix metalloproteinase 9 by activated protein $\mathrm{C}$ : Relevance to inflammation in rheumatoid arthritis. Arthritis Rheum 2007; 56:2864-74.

21. Silosi I, Cojocaru M, Foia L, Boldeanu MV, Petrescu F, Surlin P. Significance of circulating and crevicular matrix metalloproteinase- 9 in rheumatoid arthritis-chronic periodontitis association. J Immunol Res 2015; 2015:218060.

22. Edwards CK, Green JS, Volk HD, Schiff M, Kotzin BL, Mitsuya H, et al. Combined anti-tumor necrosis factor-alpha therapy and DMARD therapy in rheumatoid arthritis patients reduces inflammatory gene expression in whole blood compared to DMARD therapy alone. Front Immunol 2012; 3:366.

23. Tchetina EV, Pivanova AN, Markova GA, Lukina GV, Aleksandrova EN, Aleksankin AP, et al. Rituximab downregulates gene expression associated with cell proliferation, survival, and proteolysis in the peripheral blood from rheumatoid arthritis patients: A link between high baseline autophagy-related ULK1 expression and improved pain control. Arthritis 2016; 2016:12. 